\title{
Social Contact for Older People with Visual Impairment Through Mastery of Smartphones: Barriers and Suggested Solutions
}

\author{
Kristin Skeide FUGLERUD ${ }^{\mathrm{a}, 1}$, Siv TUNOLD ${ }^{\mathrm{a}}$, Kristin KJÆRET ${ }^{\mathrm{b}}$ \\ ${ }^{a}$ Department of Applied Research in Information Technology, Norwegian Computing \\ Center, Norway \\ ${ }^{\mathrm{b}}$ Norwegian association of the blind and partially sighted, Oslo, Norway
}

\begin{abstract}
Older people with visual impairment are more prone to feeling lonely than their seeing peers. Research suggests that learning to use smartphones can improve psychological well-being in older adults. We seek to further explore and find solutions to three barriers for increased use and mastery of smartphones by older people with visual impairment, namely how to a) reach and motivate this group to learn to use a smartphone; b) improve the provision of training for this group, and c) organize support after training to increase the possibility for continued use. Data is collected through interviews and meetings with various stakeholders on a national and local level in Norway. Based on the results we provide some recommendations for future work to lower the barriers and to improve inclusion of older people with visual impairment into the information society.
\end{abstract}

Keywords. Older people with visual impairment, social contact through smartphone, digital skills, ICT training and support needs, mastery and autonomy, independence, universal design

\section{Introduction}

As we get older, particularly as we reach 60 and beyond, our visual function deteriorates. Therefore, the proportion of people with visual impairment in the population increases with age and aging populations.

Older people with visual impairment (VI) have a higher risk of social exclusion and of feeling lonely than their seeing peers (Brunes, B Hansen and Heir, 2019). Almost one in two adults with visual impairment experience moderate or severe loneliness. The rates of loneliness among people with VI is consistently higher across all age groups compared to the general population. For people aged 66 years and older the prevalence of moderate and severe loneliness among VI was 31 percent compared to 22 percent in the general population. In a survey about the effects of isolation and social distancing on people with vision impairments $(\mathrm{N}=973)$, the use of technologies to make the most of a difficult situation, was the most agreed upon coping strategy [18]

${ }^{1}$ Corresponding Author, Kristin Skeide Fuglerud, Department of Applied Research in Information Technology, Norwegian Computing Center, Norway; E-mail: Kristins@nr.no. 
More and more services in today's society are digitized, and the European Commission as well as the European industry has launched strategies for an even stronger digital transformation moving forward. Both the United Nations and the European Commission recognize that removal of digital accessibility barriers and investing in digital skills is crucial for independent living and an imperative for achieving the Sustainable Development Goals [4,23].

Increasingly more research supports the connection between adult learning and learners' subjective wellbeing and health, with even greater benefits for vulnerable groups [15]. Training in digital skills for older people can increase their opportunities to maintain social networks, reduce the feeling of separation due to physical distance barriers, and increase the sense of inclusion and belonging in the information society [10]. The use of smartphone apps can also motivate and enable older people to engage in a healthy lifestyle, adhere to medication regimen, monitor, and manage chronic diseases, and perform instrumental activities of daily living [25]. For people with VI smartphones can function as multi-purpose tools that facilitate independence in increasingly diverse contexts [14].

However, the use of smartphones is less prevalent among older people with VI than among sighted people in the same age group [16]. Reasons for this may relate to personal economy, education, and work experience. Another important reason may be that it is more demanding to learn and use a smartphone for visually impaired people than for seeing people. In previous projects $[6,8,9]$ we found that older people with visual impairment need special training and readily available technology assistance and followup after the training. We also found that sighted friends and others in the home environment, including young people, had little knowledge about how to use the settings and functionality that enable visually impaired people to use a smartphone. Therefore, it is not easy for older people with VI to get informal help from friends and relatives.

According to Norwegian legislation, people who have not received training in basic digital skills have the right to such training [21]. The Norwegian authorities have also stated that this includes training in how to use a smartphone for people with visual impairment [22]. However, the training services vary widely between municipalities for older people with VI. Long waiting lists to smartphone courses given by the Norwegian Association of the Blind and Partially Sighted (NABP) indicate that the municipal services do not meet the need.

Based on these challenges and experiences, the aim of the project was to further explore and seek to find solutions to three barriers for increased use and mastery of smartphones by older people with visual impairment, namely how to a) reach and motivate this group to learn to use a smartphone; $b$ ) improve the provision of training for this group, and c) organise support after training to increase the possibility for continued use.

\section{Background}

Universal design of Information and Communication Technology (ICT) is an important strategy to foster inclusion of people with disabilities in the information society, on an equal basis with others. Universal design is recommended as a strategy to achieve accessibility by the UN Convention on the Rights of Persons with Disabilities (UNCRPD)[24]. The EU plays an important part to this end by promoting universal design and accessibility of ICT through legislation, such as Directive 2016/2102 on the 
accessibility of websites and mobile applications of public sector bodies and the European Accessibility Act (EEA) [1]. Although there is a long way to go before most apps and websites are universally designed [5], there are now an increasing number of apps that are accessible for people with visual impairment [14].

This study is conducted in Norway; one of Europe's most digitised societies. Norway is among the countries in Europe with the highest proportion of citizens with digital skills above basic level [2]. Numbers from Statistics Norway show that 75 percent of the population aged 65-74 years and 54 percent aged 75-79 years owned a smartphone in 2020, and that 92 percent of the population used the internet daily [20]. About half of Norwegians 80 years and older use a smartphone [2]. The COVID-19 pandemic has accelerated the use of technology and the internet. 41 percent of Norwegians have experienced a greater need for digital skills because of the corona situation [2].

The Norwegian government's goal is to get as many citizens as possible to communicate digitally with both local and central authorities [13]. Moreover, the public sector shall facilitate equal participation in society for all inhabitants, regardless of ability or life situation. An important success factor to achieve this equality is to implement universally designed public services. It also requires citizens to have sufficient digital skills to use digital services.

A nationally representative survey in Norway shows that despite high levels of digital skills in the population, 67 percent of the respondents experience a need to further strengthen their digital skills [2]. Among barriers to further strengthen their skills, 17 percent of the population state the lack of universally designed solutions, and 10 percent state the lack of training opportunities to learn to use assistive technology or special settings for people with disabilities (ibid.)

Previous research has identified a number of challenges older adults face when learning to use information technology [12]. These challenges seem to be exacerbated for older adults with VI due to a variety of factors. This includes low self-efficacy, the time and assistance needed for training and learning, challenges of inaccessible software and frequent changes in the software and changing visual abilities of the individual [17].

In order for people with VI to be able to use the touch screen of a smartphone, they must enable a special setting that provides screen reader functionality (e.g VoiceOver on iOS and Talkback on Android). This is a standard feature on many types of smartphones. When using this functionality, the interface will change its behaviour. The interface becomes more audio based, reading the content on the screen out loud through synthetic speech. To navigate one will use special gestures. These gestures are specific to each operating system and are techniques that seeing people usually have little or no knowledge of.

In previous projects we found that general training programs for older people in learning to use technology are not suitable for people with VI [6,9]. Such programs usually assume that participants can see and follow visual demonstrations, and do not provide instructions in the specific techniques that people with VI need. Also, practicing audio-based functions in a group setting is far from ideal.

In previous projects we also found that sighted friends and others in the home environment, including young people, have little knowledge about how to use the settings and functionality that enable visually impaired people to use a smartphone $[6,7,9]$. Thus, it is not easy for older people with VI to get informal help from friends, relatives, or random volunteers. Therefore, we argue that older people with VI in general need special training by teachers that are knowledgeable about the functionality and techniques visually impaired people rely upon to be able to use smartphones. We also 
found that these learners need readily available technology assistance and follow-up after the training. Among the reasons for this is the frequency of inaccessible content, including error messages, and the lack of knowledge among sighted peers. Other research confirms this picture. A survey with 56 blind participants highlighted difficulties in getting necessary technical assistance for blind people [11]. Comments from the survey participants conveyed lack of knowledge among sighted people to be able to support users of screen reading technology when accessibility, usability or technical issues occurred.

Other research also points to the need for people with VI to attend specialized classes, one-on-one training, patience and recognizing that the training takes time. Gesture-based interactions of a smartphone require extensive training. The failure to recognize this is highlighted as an important reason for reduced access to the digital community for people with VI [3]. A survey by Martiniello et al. [14] found that people who acquired their vision loss after the age of 60 were more likely to rely upon professional training to be able to use smartphones. Younger people could rely more upon self-learning and webbased resources (Ibid.). It is recognised that the high level of social and technical support required to use smartphones for older people with VI may increase the divide between those older adults who do and do not successfully adopt such technologies [17].

To motivate older people with VI to learn new technology it is important to describe the benefits of the technology [17]. A study among people with VI aged 61-100 years found that 25 percent of the respondents with impairments believe they have extra benefits using internet-based services compared to the general population [19]. Among the main reasons why older people want to master digital tools are access to updated information, to be able to perform services from their home, stay in touch with family and friends, to increase their opportunities to participate in organisational work and social life, and for entertainment [19].

Mainstream devices such as smartphones are frequently and increasingly used amongst visually impaired adults in place of, or in combination with, traditional assistive aids for specific tasks. One study found that users across all ages with higher selfreported proficiency were more likely to select a mainstream device over a traditional assistive device [14]. The ever-increasing number of accessible and useful apps is one important reason that the large majority of people with VI prefer mainstream smartphones to special purpose assistive technology. This despite drawbacks, such as a steep learning curve, the prevalence of inaccessible apps and cumbersome text editing. This important trend comes with new opportunities that should be considered. The authorities should consider opportunities of offering training and support in the use of smartphones as a possible alternative or supplement to the training and use of special purpose assistive technologies.

To summarize, we find broad support in the literature on the importance of enabling people with VI to learn and use smartphones for mastery, self-management, and social inclusion. The literature also underscores that this requires specialized training. However, we have found little discussion in the research literature on how to reach and motivate older people with VI, to best organize the training, and how to organise the necessary follow up and support after the training. 


\section{Participants and methods}

The target group of this paper is visually impaired persons over the age of 60 , who are not at work and are at extra risk of experiencing loneliness. We define this to be people who live alone, have a small social network, and/or have problems participating in social contexts due to reduced mobility or independence. Furthermore, we restrict the target group to people with VI who need training in basic digital skills.

The study discussed in this paper is part of a series of collaboration projects with The Norwegian Association of the Blind and Partially Sighted (NABP). These projects have investigated the learning needs and training experiences of the target group, through interviews and participant observation of a training program (Fuglerud, Chan and Hilde T. Sørli, 2018; Fuglerud, Chan and Hilde Tuhus Sørli, 2018; Fuglerud et al., 2019). The current project focuses on the organisational aspects [8].

In 2019, we conducted four meetings with various stakeholders and eleven interviews. The focus of both the stakeholder meetings and interviews was to gain insight into the participants opinions on the three main research questions. The stakeholder meetings followed an agenda with the tree main research questions and sub questions. The interviews followed a semi-structured interview guide aiming at highlighting the same themes and was conducted as telephone interviews. We asked about how to reach and motivate the target group. We wanted to gain insight into the participants' experiences on how to train older people with VI in the use of smartphones and ICT. We wanted to know their opinions on the organisation of the training and how to best carry out the training. We asked about who is or should be responsible for support and followup after training, and about their thoughts on a telephone support service.

Table 1. Overview of stakeholder meetings

\begin{tabular}{llc}
\hline Roles & Region & No. of participants \\
\hline Principals of adult teachers & Municipalities in Vestfold & 9 \\
\hline $\begin{array}{l}\text { visual contacts, Adult teachers, NABP } \\
\text { representatives, Experts in ICT teaching for VI }\end{array}$ & $\begin{array}{l}\text { Vestfold County and two } \\
\text { experts from a national level }\end{array}$ & $10+2$ \\
\hline Red cross and a public volunteer centre & Vestfold County & 3 \\
\hline Reference group and the project group & National level & $6+4$ \\
\hline
\end{tabular}

The stakeholder meetings included personnel from public and private organisations, both at a local and national level, see Table 1. The NABP's local county team in Vestfold helped organize the local meetings. One meeting included principals of the adult education units (VO) of the municipalities in Vestfold County. A second meeting included local participants from public and private organisations in the region Vestfold; public visual contacts from several municipalities; a counselling firm which offers various services for people with VI (such as assistive technology and training), a teacher from an adult education unit and visually impaired and sighted members and employees of NABP. A third meeting included participants from other non-governmental organisations and a public volunteer centre. The last meeting was with the project reference group with participants representing a national point of view. This included participants from:

- Competence Norway, a directorate under the Ministry of Education and Research. Their main goal is to enable lifelong learning, and to ensure that society has the competence it needs

- Statped, a national service for special needs education 
- Norwegian Labour and Welfare Service (NAV), Department of assistive technology

- Two other non-governmental organisations, namely Red-Cross and Seniornet

- MediaLT, a research and development firm within universal design and accessibility; and participants from the project group.

Additionally, we observed a national conference on vision for personnel working in the adult education units in municipalities.

We conducted eleven interviews with participants from three different counties in Norway, see Table 2. All the interviewees had some experience with older people with VI and their use of smartphones. The interviewees were from the Vestfold, Viken, and Møre and Romsdal counties. Five of the interviewees held the position of "visual contacts" in the municipalities in Vestfold county. Two of the interviews were ICT teachers with experience from teaching older people with VI to use a smartphone. Four interviewees worked for the Norwegian Association of the Blind and Visually Impaired (NABP). Their tasks included to organize, refer and encourage people with VI to seek municipal or private training.

Table 2. Overview of interviews

\begin{tabular}{llc}
\hline \multicolumn{1}{c}{ Role } & \multicolumn{1}{c}{ Region/place } & Gender \\
\hline Public visual contact & Municipality in Vestfold County & man \\
Public visual contact & Municipality in Vestfold County & man \\
Public visual contact & Municipality in Vestfold County & woman \\
Public visual contact & Municipality in Vestfold County & woman \\
Public visual contact & Municipality in Vestfold County & man \\
NABP employee & Vestfold County & woman \\
NABP employee & Østfold County & man \\
NABP employee & Østfold County & man \\
Public ICT teacher & Østfold County & man \\
Public ICT teacher & Møre \& Romsdal County & woman \\
NABP employee & Møre \& Romsdal County & woman \\
\hline
\end{tabular}

Most Norwegian municipalities have visual contacts. In many municipalities, this is not a full-time position. Usually, it is an occupational therapist that has this responsibility as part of their position, and it is often only part time (sometimes 20 percent of a full position). The responsibility of a visual contact is, among other things, to assess the need for assistive devices. During home visits, the need for assistive devices is mapped, testing is done, and help is given to fill in necessary application forms. The majority of the interviewed visual contacts had long experience working with older people with VI.

Detailed notes from meetings and interviews were taken. We used thematic analysis to explore this material, by searching for and identifying themes across the detailed notes from both meetings and interviews. The process was first deductive, by sorting text phrases into main categories defined by the research questions. The categories were further divided and fine-tuned through inductive analysis of the text. In the following, we refer to those who participated in meetings and interviews as participants.

Based on previous findings that older people with VI need readily available technology support, the project also established and piloted a telephone-based support service for the target group. To facilitate evaluation of this service, the support personnel recorded various parameters of each call. Based on the thematic analysis and analysis of recordings from the telephone service usage, we discuss main barriers and possible solutions. 


\section{Results}

\subsection{Results from interviews and stakeholder meetings}

A key finding from the interview survey, is the participants' opinion that technology can help open new doors and opportunities for people with VI. The participants reflected on how increasingly more services in society are being digitized. Knowing how to use technology allows for more community participation. It can also increase independence to a considerable extent, and it may also reduce the loneliness of older people. However, the participants also reflected on how technology may limit older people with VI's participation in society. When an older person becomes visually impaired, a seeing relative often takes over the digital tasks. This may lead to dependency and loss of freedom, and even isolation. Therefore, the participants were concerned of lack of opportunities and the need to find ways to ensure older people with VI the necessary digital competence.

Both the interviewees and the other stakeholders clearly stated the necessity of specialized training for older people with VI. The teacher should have both technical expertise in the special settings and functions that people with VI use, and good pedagogical skills. Ideally, they should have formal competence in pedagogics and special needs education for people with VI. However, because of the lack of training resources and capacity in many municipalities, some of the stakeholders expressed that the municipalities are too strict on the requirement of formal education in pedagogics and special needs.

Regarding the training program, the participants stressed the need for one-on-one training, adapting to the pace of the learner, the need for many repetitions and easy access to help and assistance. They emphasized that the training level must be adjusted individually.

Older people with VI, who have not previously received public basic training in digital skills, are legally entitled to training in the use of a smartphone in Norway. The adult education unit in the municipality is responsible for the training. However, a main challenge is that many municipalities do not have the necessary expertise to offer such training. In many cases, neither the visual contacts nor the adult education unit have the necessary technical nor pedagogical competence to provide adequate smartphone training for older people with VI. However, there were some encouraging exceptions, which we will come back to below.

In cases where the municipality has the necessary training expertise, they often have insufficient capacity to meet the needs. In many municipalities there are long waiting lists to get training, in some places up to a year. Some of the interviewees identified this is a main obstacle for motivation. Older people with VI are also often unwilling to buy a new smartphone when it is uncertain if they will receive adequate training and followup. Many older people with VI are not aware of the possibility for visually impaired persons to use a smartphone, nor of their rights to receive training. Some of the visual contacts admitted that they were reluctant to encourage older people with VI to apply for smartphone training because of the non-existent or deficient training capacity in their municipality. Therefore, the waiting lists might have been even longer if the target group had been more directly informed and encouraged to apply.

The participants also spoke about the need for continuity, long term training and the need for support and follow up after the training. Many visually impaired people do not seek assistance from their relatives, as they do not want to be a burden. They rather wait 
until they can get help from others [6]. Also, they may not necessarily have relatives or friends to ask. A known problem is that after receiving training, technical problems may easily occur, e.g., because of software updates. If it takes too long before help is available, there is a risk that the learners forget much of their newly acquired skills.

Often, responsibility for support after completion of training is non-existent. Participants call for clearer frameworks and guidelines on how this should be organised. In the best municipalities, they had invested in special education of some of their personnel at the adult education unit. In these municipalities they work actively to find smart ways to utilize their training resources. For example, they emphasize dividing the available resources into training and follow-up, with time to practice skills and become confident between sessions. They initially teach the students sufficient skills so they can start exploring and learning more by themselves. They also utilize distance follow-up via skype when possible and offer to help with simple questions after the training is completed.

To increase motivation, participants thought it important to find good examples of useful applications and functions with very low learning threshold, such as using Siri on the iPhone to make a call or read a newspaper. Additionally, stakeholders and older people with VI themselves described how new types of health and welfare technology can enable a new level of self-management and independence. One such example is the use of an accessible app for management and reading of blood sugar levels for people with diabetes. After learning how to use a smartphone, blind people with diabetes can use an app to have the blood sugar read out loud just by enabling the text to speech functionality on their smartphone. The smartphone communicates with a sensor placed on their arm. They are no longer dependent on having another person nearby to read their blood sugar levels. Visually impaired people experience this technology as extremely helpful, particularly during the night, but also during the day when they can be independent of others. This is a good example of how knowledge of new technology with its possibilities can motivate older persons with visual impairment to seek smartphone training.

Differences in interpretation of legal clauses lead to quite different practices between municipalities. It seems that one of the interpretations leads to a more flexible practice with shorter waiting times as a result.

\subsection{Piloting a telephone support service}

During the project, we piloted a telephone support service in nearly three months, from first of October until 19th of December 2019. The service was open eight hours per week, divided into two hours per day from Monday to Thursday. The purpose of the telephone service was to provide support to older people with VI who already have basic skills in using smartphones as well as to gain more insight on how this kind of support can be organised. In particular, we wanted to know how many calls were coming and to what extent it was possible to help solve the caller's challenges. We wanted to know how easy or difficult it would be to use telephone assistance when the caller cannot see what is going on the screen. One possibility in such situations is the use a remote support software (TeamViewer QuickSupport). With the permission of the caller, this software enables the support personnel to log on to the caller's smartphone, and this can be a help in the troubleshooting process.

We developed information materials about the telephone service with detailed instructions on how to use the QuickSupport service. The information material was 
distributed broadly through the Norwegian Association of the Blind and Partially sighted (NABP). SMS with information about the telephone service was sent to all members of NABP over 60 years who had provided a cell phone number, and an e-mail with information was sent to all municipalities in Norway. The number of calls was considered good in the Norwegian context, and as a sign that service was needed, especially considering it takes time to establish and make such a service known to the target group.

During the pilot period, several parameters were registered. There were 101 calls, with a duration from 1 to 30 minutes, with an average of 7.6 minutes. Ten of the callers had a local helper. The majority of the callers had an iPhone (88). 77 of the callers used a screen reader, 19 used large font and the remaining were unknown. Many received answers to their problems (79). Many of the conversations involved the use of apps (39). There were six conversations about very basic things, while many, 23 conversations, were about using contact list, messages, and ringing. For people with VI, accessibility settings are very important to be able use the phone appropriately, and 9 of the calls were about such issues.

\subsection{Involving volunteers}

While there seems to be a general agreement among interviewees and stakeholders that training of older people with VI is and should continue to be a municipal task, several ideas have emerged about how to involve volunteers as a resource in a follow-up and support service. This will be important regarding the loneliness aspect. In previous projects, we found that family and volunteers generally do not have the necessary skills to be able to provide basic training in the use of smartphones for older people with VI $[6,7,9]$. Therefore, we raised a question about what role volunteers could have in discussions with several non-governmental organisations, such as Red Cross nationally and locally, Seniornett, and a municipal volunteer centre.

In the mentioned previous projects, we found that older people with VI sometimes were reluctant to contact the telephone-based support services because of uncertainty. They would worry about how to explain the problem when they could not see the screen, and they were worried that they would not understand what to do. We envisaged that volunteers could assist in such cases by being able to see and explain what is happening on the screen, and that it would feel safer to approach the telephone service together. In other words, the idea was that a seeing volunteer could assist with receiving help from the telephone support service.

The volunteer stakeholders were positive to this suggestion but underscored that it is necessary to provide basic training and information to the volunteers to give them a basic understanding of how the gesture and speech-based interface works. It is also necessary to give the volunteers training and guidelines regarding questions of privacy and ethics, for example related to settings where they may get access to information of a sensitive and economic nature. Furthermore, it was mentioned that there are currently few ICT-related tasks within traditional NGOs work, and that they probably have members who would be interested in such work. Finally, they stressed the need for good planning and coordination to achieve successful cooperation with voluntary organisations. It was emphasized that to keep motivation, there should be systems in place to quickly connect those who need help with the helpers, especially if the volunteers have received a particular training for this type of work. 


\section{Summary and recommendations}

As introduced, the aim of the project was to further explore and seek to find solutions to three barriers for increased use and mastery of smartphones by older people with visual impairment, namely how to a) reach and motivate this group to learn to use a smartphone; b) improve the provision of training for this group, and c) organise support after training to increase the possibility for continued use.

When it comes to reaching and motivating older persons with VI, we find that many municipalities lack awareness on the potential of technology for increased independence of persons with VI and reducing their risk of loneliness. Visual contacts do not focus on motivating older persons with VI to seek and apply for training to learn how to use smartphones. This is partly because smartphones are not listed as an assistive device and therefore not included in the tasks of the visual contacts. The visual contacts seem not to be familiar with simple techniques for persons with VI, such as using "Siri." In some cases, the visual contacts are reluctant to advise persons with VI on the use of smartphones and raise awareness on their rights to training. This is because they know the municipality does not offer sufficient training possibilities.

Based on the findings we see the need to raise awareness about the rights of the target group, the need to make the target group's needs visible, and to develop and distribute motivational material for the target group and their helpers. We suggest preparing information material to raise awareness on how use of smartphones can increase independence of persons with VI and reduce their risk of feeling lonely and prone to depression. We also suggest preparing information material targeted to the municipalities, including visual contacts, urging them to advise persons with VI on their rights to receive training and assist with their application. Additionally, we would suggest that training in low threshold use of smartphones for people with VI could enable the visual contacts to expand their service. This also requires municipal leaders to prioritize both competence and allocation of time to enable visual contacts to implement the work.

To improve the provision of training for older persons with VI it is important that the teacher have both technical competence on the specific settings and techniques that people with VI need when using a smartphone, and sufficient pedagogical competence, including patience. It is also important to allocate sufficient time and personnel to ensure one-on-one training, especially in the beginning. Most of the personnel at the adult education unit and some of the visual contacts were aware of online resources developed by Statped, including e-learning courses. However, such training of municipal vision contacts has little focus and priority in the management of the adult education unit. It is necessary to allocate time for personnel to acquire the necessary skills.

The best municipalities emphasise that the training can be more comprehensive and efficient when the teacher focuses on teaching the students enough skills for them to start exploring and learning more by themselves. They should also give the students time to practice their skills and become confident between sessions, and make themselves accessible for simple questions in between sessions, including e-mail or by utilizing distance follow-up via skype or similar tools.

The improved accessibility of useful mainstream applications such as audiobooks, applications which provide optical character recognition, colour recognition and many more, can increase access to information that were not available to persons with VI 
before. It can also reduce the need for many single purpose assistive devices. Moreover, new and accessible apps combined with health and welfare technology can give people with VI completely new opportunities for mastery and independence. At the same time, it must be recognised that mainstream smartphones cannot replace the use of traditional tools for the completion of certain tasks, for example tasks that include the need for extensive typing and editing. Nevertheless, a shift towards more universally designed mainstream technology can have many benefits, such as reduced costs for special purpose devices, increased portability, and reduced stigma.

We see that many municipalities are lagging behind. This includes identifying and supporting smartphones as a multi-purpose tool to facilitate independence in increasingly diverse contexts. This trend highlights the need for municipalities and trainers to focus on enabling older people with VI to learn to use smartphones. We recommend municipalities to initiate discussions on the professional, administrative, and legal aspects of this and improve the implementation of the right to training in smartphones of persons with VI. We also plan to target managers and employees of adult education units through national seminars to present these results and examples of what the municipalities that fulfil obligations to the target group are doing.

Regarding the organisation of support after training to increase the possibility for continued use of the smartphone, there is currently very limited service. The available hours given for the training by the teacher at the adult education unit should include some hours for later follow up. The telephone support service was well received by all the stakeholders, including the users of the service, Statped, the adult education units and the visual contacts. There was a common understanding that this kind of service is necessary to ensure that training in the use of smartphones materializes to long-term use of smartphones.

The experiences from the piloted telephone support service were encouraging. In 78 percent of the cases, the telephone support service was able to solve the issue at hand. We will continue exploring how this can become an integrated part of the government's services for the visually impaired, as it seems to be a key measure to enable persons with VI to utilize and maintain the skills developed during training. It is also an important measure to ensure continued use of smartphones when technical problems arise, e.g., due to software updates.

Another measure to further reduce the barriers is the use of supportive volunteers. This was positively received by the volunteer organisations we consulted in the project. We will continue to explore how to engage and organise volunteers, both as a measure to reduce loneliness for the target group, as well as a motivational factor to continue learning new ways of using the smartphone for increased mastery and independence.

Based on the findings we recommend continuing with the telephone-based support service and to further explore how to include volunteers interested in technology.

\section{Conclusion}

To meet the challenges of an aging population, authorities in many countries are investing in healthcare apps and independent living technologies. Many such solutions can contribute to increased digital social contact and independence for older people. As populations are aging globally, there is an increase in the prevalence of people with visual impairment. 
Universal design is an important strategy to foster inclusion of people with disabilities in the society. Policy and legislation in many countries play a significant role in promoting and requiring digital solutions to be universally designed and accessible. There is an increase in the number of useful apps and independent living technologies accessible for people with VI. Even when universally designed, most digital solutions require that the user has basic digital skills. To realize the rights of persons with disabilities, in line with the UNCRPD, authorities need to ensure both universally designed solutions and the digital skills of the users.

Our interviewees and stakeholders identified several barriers to effective inclusion of older people with VI into the information society. Most older people are dependent on training to acquire the necessary skills. However, courses in smartphone training usually do not accommodate people with VI. There is a lack of suitable training services in basic digital skills for older people with VI. Among the barriers to acquiring the necessary digital skills for older people with VI are 1) a lack of information about the relevance and usefulness of technological solutions and training opportunities; 2) unclear responsibilities within municipalities regarding who should motivate and inform the target group about public training services; 3 ) varying resources and competences in the municipalities; 4) lack of resources for competence development within municipalities; 5) varying and different priorities within municipalities; and 6) lack of routines for systematic follow-up and support for older people with VI.

Addressing these barriers has the potential to increase the quality of life for older people with visual impairment and reduce the feeling of loneliness. This requires strategic work by municipal leaders to invest in competence and allocate sufficient time to implement training services. We have also outlined some suggestions and plans to lower the barriers. This includes development of informational and motivational material for persons with VI and municipal leaders and employees. Presentations and discussions at national adult education seminars and similar will also increase awareness on the issue. Finally, we will highlight the importance and usefulness of establishing a permanent public support service in the use of technology for people with VI.

We conclude that there is a need to ensure access to suitable training services in basic digital skills for older people with VI. This will enable people with VI to utilize apps and independent living technologies that are universally designed. This has the potential for increased social contact, independence, and a feeling of mastery for the visually impaired. It will also contribute to increased sustainability for a wide range of technological solutions in our society, and not least solutions introduced to meet the challenges posed by the aging population.

\section{Acknowledgement}

We are very grateful to the participants in the interview survey and stakeholder meetings, to personnel in the telephone support service. The project was funded by the partners own contribution and by a grant from a program for development and testing of technological tools to mobilize against loneliness among elderly people in the Norwegian directorate for health. 


\section{References}

[1] AGE Platform Europe, The European Accessibility Act published in EU Official Journal, The Voice of Older Persons at EU Level. (2019). https://age-platform.eu/policy-work/news/european-accessibilityact-published-eu-official-journal.

[2] A.M. Bjønness, T. Midtbø, H. Størset, and C.H. Ulven, Befolkningens digitale kompetanse og deltakelse: Med et ekstra blikk på seniorer og ikke-sysselsatte, Kompetanse Norge, 2021.

[3] R.J.P. Damaceno, J.C. Braga, and J.P. Mena-Chalco, Mobile device accessibility for the visually impaired: problems mapping and recommendations, Universal Access in the Information Society. 17 (2018) 421-435.

[4] EC, Union of Equality Strategy for the Rights of Persons with Disabilities 2021-2030, European Commission, Brussels, 2021. doi:10.2767/31633.

[5] D. Ferri, and S. Favalli, Web Accessibility for People with Disabilities in the European Union: Paving the Road to Social Inclusion, Societies. 8 (2018) 40.

[6] K.S. Fuglerud, R. Chan, and H.T. Sørli, Studying Older People with Visual Impairments Using Mainstream Smartphones with the Aid of the EziSmart Keypad and Apps, Studies in Health Technology and Informatics. 256 (2018) 802-810.

[7] K.S. Fuglerud, R. Chan, and H.T. Sørli, EziSmart - verktøy for mestring og sosial samhandling mellom synshemmede eldre, pårørende og andre. Prosjektrapport, Norsk Regnesentral, 2018.

[8] K.S. Fuglerud, K. Kjæret, and S. Tunold, iStøtet - IT-støtte for synshemmede eldre: Inkludering i informasjonssamfunnet - motivasjon, opplæring og oppfølging, Norsk Regnesentral og Norges Blindeforbund, 2020.

[9] K.S. Fuglerud, H.T. Sørli, I.K.L. Ottem, and R. Chan, EziSmart videreføring: Sosial kontakt for synshemmede eldre gjennom mestring av smarttelefon, Prosjektrapport, Norsk Regnesentral, 2019.

[10] E. Gabarron, H. Hoaas, and E. Johnsen, Kunnskapsoppsummering: Sosial, digital kontakt for å motvirke ensomhet blant eldre, Nasjonalt senter for e-helseforskning, 2016.

[11] A. Jarry, C. Chapdelaine, S. Kurniawan, and W. Wittich, Blind Adults' Perspectives on Technical Problems and Solutions When Using Technology, Journal of Blindness Innovation and Research. 7 (2017). doi:10.5241/7-130.

[12] Y.S. Kim, Reviewing and Critiquing Computer Learning and Usage Among Older Adults, Educ. Gerontol. 34 (2008) 709-735.

[13] KMD,

Digitaliseringsrundskrivet, https://www.regjeringen.no/no/dokumenter/digitaliseringsrundskrivet/id2826781/ (accessed 11.2 2021).

[14] N. Martiniello, W. Eisenbarth, C. Lehane, A. Johnson, and W. Wittich, Exploring the use of smartphones and tablets among people with visual impairments: Are mainstream devices replacing the use of traditional visual aids?, Assist. Technol. (2019) 1-12.

[15] M. Narushima, J. Liu, and N. Diestelkamp, Lifelong learning in active ageing discourse: its conserving effect on wellbeing, health and vulnerability, Ageing Soc. 38 (2018) 651-675.

[16] Opinion, Undersøkelse om IKT-bruk utført for Norges Blindeforbund, (May 2019). https://www.blindeforbundet.no/om-blindeforbundet/filer-undersokelser/undersokelse-omsynshemmedes-ikt-bruk-til-synshemmedes-aksjonsuke-mai-2019.

[17] A.M. Piper, R. Brewer, and R. Cornejo, Technology learning and use among older adults with late-life vision impairments, Universal Access in the Information Society. 16 (2017) 699-711.

[18] J. Rickly, N. Halpern, M. Hansen, S. McCabe, and J. Fellenor, Covid-19: The effects of isolation and social distancing on people with vision impairment, University of Nottingham; Kristiania University College; Wrexham Glyndwr University; The Guide Dogs for the Blind Association, 2020. http://doi.org/10.17639/nott.7074 (accessed Oct. 31, 2020).

[19] D. Slettemeås, H. Mainsah, and L. Berg, Eldres digitale hverdag: En landsdekkende undersøkelse om tilgang, mestring og utfordringer i informasjonssamfunnet, Forbruksforskningsinstituttet SIFO OsloMet - storbyuniversitetet, 2018.

[20] Statistics Norway, Bruk av IKT i husholdningene, Forsiden $>$ Teknologi og innovasjon $>$ Bruk av IKT $i$ Husholdningene. (2020). https://www.ssb.no/statbank/list/ikthus (accessed October 31, 2020).

[21] UDIR, Voksnes rett til grunnskoleopplæring etter opplæringsloven kapittel 4A Udir-3-2012, (n.d.). https://www.udir.no/regelverkstolkninger/opplaring/Voksne/Udir-3-2012/2-Grunnskoleopplaring-etter-4 A-1/ (accessed March 30, 2020).

[22] UDIR, Spørsmål om svaksynte og blindes rettigheter etter opplæringsloven, (7. juni 2018). https://www.udir.no/regelverkstolkninger/opplaring/Elever-med-sarskilte-behov/sporsmal-omsvaksynte-og-blindes-rettigheter-etter-opplaringsloven/.

[23] UN, Disability and Development Report: Realizing the Sustainable Development Goals by, for and with persons with disabilities. 2018, United Nations, Department of Economic and Social Affairs, 2019. https://social.un.org/publications/UN-Flagship-Report-Disability-Final.pdf. 
[24] UNCRPD, Convention on the rights of persons with disabilities (CRPD), United Nations. Department of Economic and Social Affairs. https://www.un.org/development/desa/disabilities/convention-on-the-rights-of-persons-withdisabilities.html.

[25] J. Wang, Y. Du, D. Coleman, M. Peck, S. Myneni, H. Kang, and Y. Gong, Mobile and Connected Health Technology Needs for Older Adults Aging in Place: Cross-Sectional Survey Study, JMIR Aging. 2 (2019) e13864. 